\title{
VOLUNTARIADO EDUCACIÓN EXACTA
}

Ing. Norberto Sanabria, Lic. Alicia Amarilla, Ing. Rubén Corvalan (*)

Palabras Claves: Educación, vulnerabilidad, extensionismo.

Resumen: Este proyecto se implementó, desde su inicio, con docentes, alumnos, no decentes y egresados de la Facultad de Ciencias Exactas y Naturales y Agrimensura (FaCENA). Con el transcurso del tiempo se han ido incorporando integrantes de otras carreras y Facultades de la Universidad Nacional del Nordeste (UNNE). Las actividades se resumen a apoyatura escolar extracurricular en sectores vulnerables de la región, llevada a cabo por Voluntarios en casas de familia, unidades educativas, iglesias, comedores comunitarios, ONGs, municipios, etc. El proyecto está destinado a niños y jóvenes, buscando la retención en el sistema educativo y la reinserción en casos de abandono. Al final de cada etapa se realizan actividades recreativas, festejos en días festivos, cumpleaños, entre otros.

Siempre este proyecto denominado "Educación Exacta" estuvo destinado a alumnos de escuelas primarias y secundarias, que requieran apoyatura escolar en materias de las ciencias exactas y naturales, principalmente. Alumnos de los últimos años del secundario para motivarlos al ingreso de las carreras universitarias, aquellos que abandonaron el sistema educativo formal y que aspiren retomar su actividad escolar, los inscriptos a las ofertas educativas de carreras de grado de la FaCENA, que deseen incorporarse a los Talleres y todos los que soliciten reforzar conocimientos de las ciencias básicas y otras disciplinas, a fin de orientarlos en el proceso enseñanza aprendizaje.

Desarrollo: Este proyecto comenzó en el año 2004 con la aprobación de la Resolución No 601/04CD, por la cual la FaCENA autoriza y auspicia la propuesta del Ing. Norberto Sanabria, docente de la Casa, quien estuvo a cargo de la dirección y coordinación hasta la actualidad, a realizar Talleres de Apoyo Escolar en las cien-

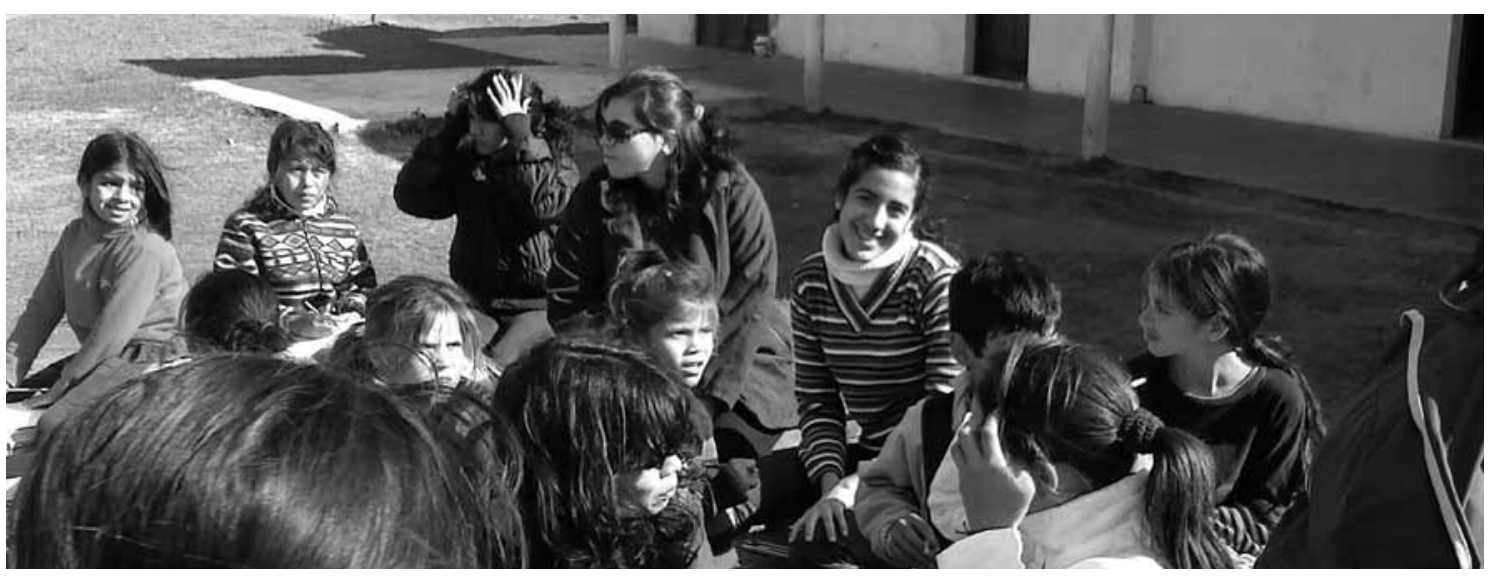

Fig. 1: Apoyo Escolar a niños en el predio de la Parroquia Bo Pirayui - Ctes

(*) Facultad de Ciencias Exactas y Naturales y Agrimensura. Av. Libertad 5470 - 3400W - Corrientes - E-mail: norbertosanabria@hotmail.com - E-mail: amarillaalicia@hotmail.com 
cias básicas, con ayuda de otros docentes, no docentes y alumnos de las carreras de ingeniería eléctrica, ingeniería en electrónica, agrimensura, licenciatura en sistemas, bioquímica, profesorados y licenciaturas en biología, matemática, química y física, egresados de la casa y profesionales del medio.

Desde su origen, se estableció expresamente la NO percepción de ningún tipo de remuneración por la realización estas actividades. Así, comunidad educativa y profesionales dieron inicio a esa tarea hasta, inclusive el año 2014.

Desde el inicio y en forma ininterrum- pida, se participa de los proyectos de Extensión Universitaria desde la Facultad de Ciencias Exactas y Naturales y Agrimensura. A partir de la aprobación del proyecto, año tras año, se ha trabajado en conjunto con distintos organismos gubernamentales y no gubernamentales, por ejemplo $\mathrm{Mi}$ nisterio de Educación de la Provincia de Corrientes, Municipalidad de la Ciudad de Corrientes, Centro de Ingenieros de Corrientes, Colegio de Bioquímicas de la Provincia, Asociaciones Civiles y fundaciones Porvenir y Dejando Huellas, parroquias como Nuestra Señora del Valle, Comedor Pókemon, etc.

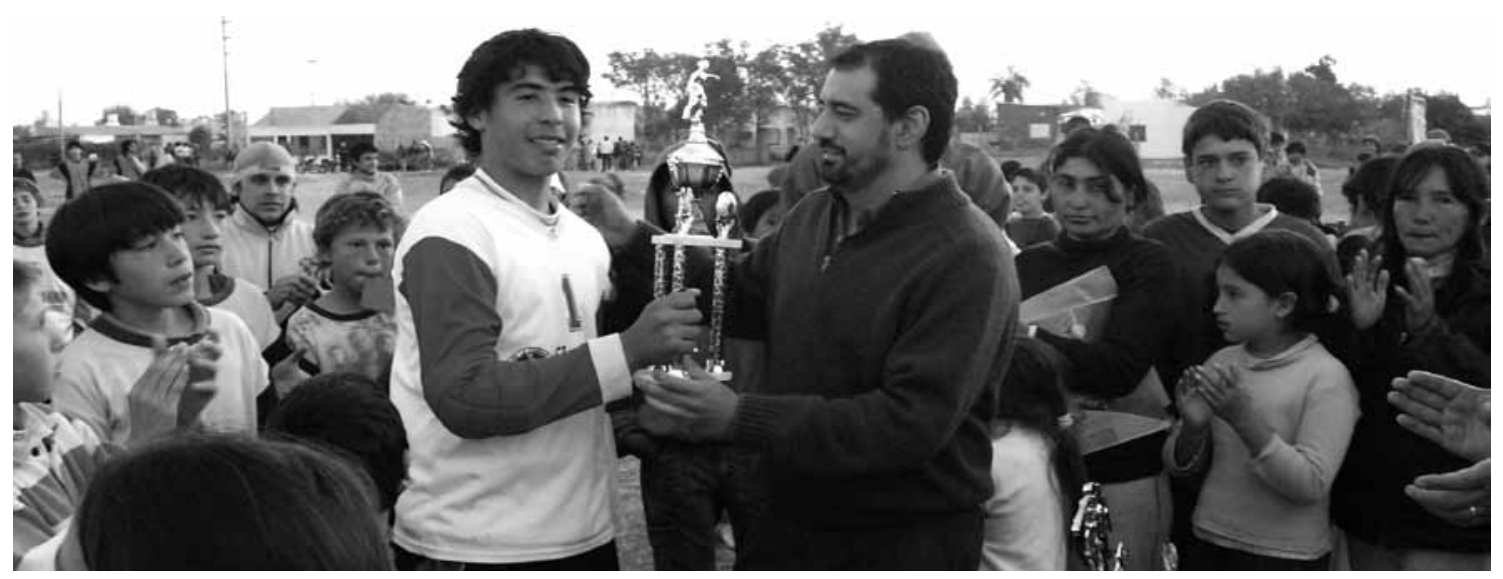

Fig. 2: Actividades Deportivas Complementarias

A través de la Resolución $N^{\circ}$ 2044/10 del Ministerio de Educación de la provincia de Corrientes, declaró de Interés Educativo el proyecto Educación Exacta para Todos; así también lo han hecho otras Instituciones públicas, debido al impacto social que representa una actividad con estas características.

El proyecto mantuvo a lo largo de tiempo el mismo objetivo, el cual es brindar Apoyo Escolar a alumnos de los Niveles Primario y Secundario de la región en las ciencias exactas y naturales (matemática, química, biología, física y tecnología) con especial énfasis a alumnos que asisten a establecimientos en condiciones de ruralidad o suburbanas y/o vulnerabilidad, incorporando como beneficiarios al nivel preuniversitario desde el año 2012. Se motiva asimismo a los Voluntarios a participar de otras actividades solidarias. Esencialmente, se busca contribuir con la integración de los alumnos de los niveles primario y secundario de la educación formal, y en especial a niños y jóvenes que asisten a escuelas rurales y suburbanas de la región, mediante la motivación y la realización de apoyo escolar en asignaturas de las ciencias exactas y naturales. Con la inclusión de clases preparatorias para el ingreso 
a la educación superior, se busca promover el ingreso a las carreras universitarias de la UNNE, como herramienta de superación individual y colectiva. Brindar mejores condiciones en el saber del aspirante. Evitar la deserción escolar y marginación social del niño / joven. Estimular y facilitar procesos descentralizados de aprendizaje orientados a alumnos en general con pocas posibilidades socio-económicas. Otorgar a los voluntarios las experiencias pedagógicas para un mejor desempeño de su labor profesional. Motivar la generación de nuevos espacios de discusión y preparación de Voluntarios Universitarios.

Enriquecida por la experiencia y con más voluntarios de la Universidad, se incorporaron charlas sobre adicciones, educación sexual, prevención de enfermedades, parasitosis, psicología social y otros temas interés en los últimos años.

Además, con la ejecución de este proyecto se ha logrado en forma indirecta cumplir la función de "formador de formadores". A través del seguimiento de los beneficiarios y voluntarios, se observó el crecimiento académico de los alumnos voluntarios quienes han pasado a ser profesionales, algunos beneficiarios han pasado a ser voluntarios.

Con el transcurrir de los años, el plantel de voluntarios se ha ido renovando, permitiendo la incorporación de padres, docentes y alumnos otras carreras de la UNNE, como medicina, kinesiología, licenciatura en RRLL, odontología, veterinaria, licenciatura en ciencias de la educación y licenciatura en comunicación social.

Los Talleres se han ido impartiendo tanto en unidades académicas de la Universidad, como también en escuelas primarias y secundarias, parroquias, comedores, centros profesionales y hasta en casas de familia.

Con estas actividades se ha demostrado

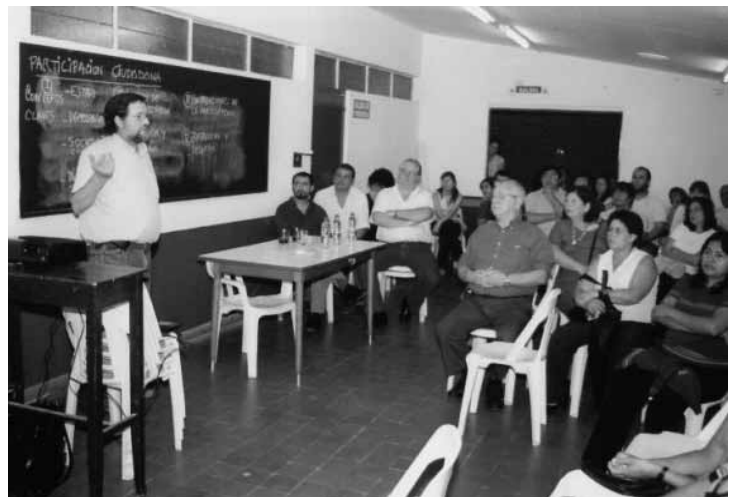

Fig. 3: Taller de Participación Ciudadana a Voluntarios

presencia de la Universidad en el Medio Social, en zonas vulnerables y/o alejadas del área urbana, beneficiando con esta actividad a más de 2000 niños y adolescentes de distintas edades, incentivando la conducta y valoración de la actividad de "voluntariados" a estudiantes universitarios, docentes, no docentes de la FaCENA y profesionales del medio en general, dando de esta manera participación a lo lardo del tiempo alrededor de 300 voluntarios.

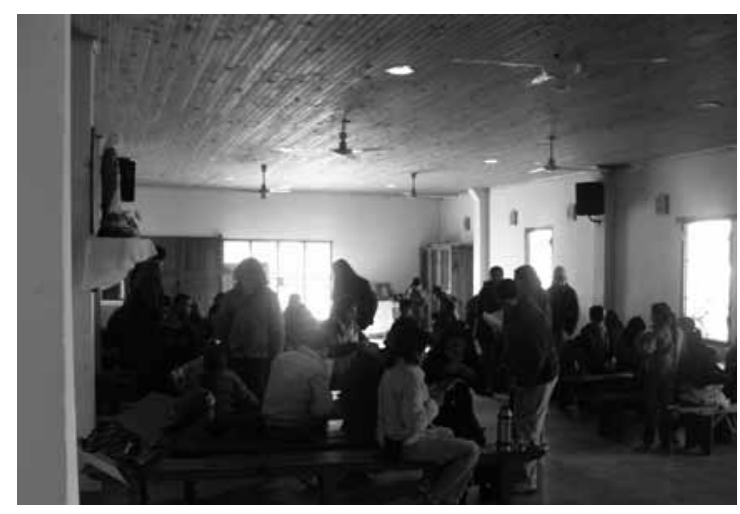

Fig. 4: Jornada con beneficiarios

Actualmente se está trabajando en la sistematización para el seguimiento escolar y académico de los beneficiarios, para lograr a mediano plazo la instalación de un Observatorio que colabore con programas formales como las tutorías, becas del bicentenario, plan PROGRESAR. 